\title{
TERRITÓRIO E DESENVOLVIMENTO NA PERSPECTIVA DOS GEÓGRAFOS DA ESCOLA DE TURIM - ITÁLIA
}

\author{
TERRITORY AND DEVELOPMENT IN PERSPECTIVE \\ GEOGRAPHERS TORINO SCHOOL - ITALY \\ TERRITORIO Y DESARROLLO EN LA PERSPECTIVA DE LOS \\ GEÓGRAFOS DE LA ESCUELA DE TURÍN - ITALIA \\ Áurea Andrade Viana de Andrade - Universidade Estadual do Paraná - Campo Mourão - Paraná - Brasil \\ aureavgeo@yahoo.com.br \\ Elpídio Serra - Universidade Estadual de Maringá - Maringá - Paraná - Brasil
serraelpidio@gmail.com
}

\section{Resumo}

0 artigo discute os paradigmas de território e de desenvolvimento local dentro do Sistema Local Territorial (SLOT), pautado nos postulados dos geógrafos italianos. Através deste, buscamos demonstrar o debate acerca dessas questões, considerando as concepções teóricas e metodológicas da Escola de Turim de Geografia, especialmente dos geógrafos Giuseppe Dematteis, Francesca Governa, Egídio Dansero, Marco Baggiani, visto que se destacam nas produções científicas, desde a década de 1960, e têm influenciado o pensamento de pesquisadores brasileiros, que buscam uma abordagem relacional e híbrida, com as relações geográficas e com as articulações territoriais para o desenvolvimento.

Palavras-chave: Território, desenvolvimento local, escola de Turim.

\section{Abstract}

The article discusses the paradigms of territory, local development and Local Territorial System (SLOT), based on the postulates of the Italian geographers. The aim is to demonstrate the debate about these issues, considering the theoretical and methodological conceptions of the Turin School of Geography, especially the geographers Giuseppe Dematteis, Francesca Governa, Egídio Dansero, Marco Baggiani, since they stand out in scientific productions since the 1960, and have influenced the thinking of Brazilian researchers, who seek a relational and hybrid approach, with geographic relations and territorial articulations for development.

Keywords: Territory, local development, school of Turin.

\section{Resumen}

El artículo discute los paradigmas de territorio y de desarrollo local dentro del Sistema Local Territorial (SLOT), basado en los postulados de los geógrafos italianos. A través de este artículo, buscamos demostrar el debate sobre estas cuestiones, considerando las concepciones teóricas y metodológicas de la Escuela de Turín de Geografía, especialmente de los geógrafos Giuseppe Dematteis, Francesca Governa, Egídio Dansero, Marco Baggiani, puesto que se destacan en las producciones científicas, de la década de 1960, y han influenciado el pensamiento de investigadores brasileños, que buscan un enfoque relacional e híbrido, con las relaciones geográficas y con las articulaciones territoriales para el desarrollo.

Palabras clave: Territorio, desarrollo local, escuela de Turín. 
Introdução

A discussão de território à luz dos geógrafos italianos tem influenciado fortemente o pensamento de vários pesquisadores, dentre os quais o professor Dr. Marcos Aurélio Saquet, geógrafo brasileiro que busca elementos e subsídios para interpretação dos territórios e das territorialidades, dadas as complexidades das relações sociais, que se constituem na atualidade. Em sua obra Abordagens e Concepções de Território, publicada em 2007, traz uma discussão da tendência relacional e híbrida, que segundo o autor é mais próxima do real. Destaca, sobretudo, as ideias do geógrafo Geuseppe Dematteis, que apresenta uma preocupação com as relações geográficas, tanto verticais, como horizontais, isto é, com as condições e com as articulações territoriais para o desenvolvimento. Do mesmo modo, devemos considerar as ideias de Claude Raffestin, geógrafo suíço, que viveu um tempo no Dipartimento Interateneo Território di UNITO e fez importantes contribuições, especialmente ao confrontar os conceitos de espaço e território. Raffestin tornou-se muito conhecido no Brasil no início da década de 1990, quando sua obra Por uma Geografia do Poder (1993) foi traduzida para o português.

Nos últimos anos, a nova geração de geógrafos da Escola de Turim vem se destacando, especialmente com as discussões de Dansero, Giaccaria e Governa (2008) sobre as concepções de cooperação descentralizada entre as universidades e organizações não governamentais, bem como importante contribuição no campo teórico-metodológico acerca do desenvolvimento local. Nessa perspectiva, o território assume uma centralidade, porém sua abordagem é muito complexa, uma vez que se trata de um conceito e de uma categoria de análise geográfica, o que nos obriga a compreensão dos pressupostos teóricos de desenvolvimento, como processo econômico, político e social que reflete na qualidade de vida da população. Assim, trata-se de uma relação dialética território/ desenvolvimento.

É importante ressaltar que discutir o conceito de desenvolvimento não é uma tarefa fácil, tendo em vista a vasta produção científica das Ciências Sociais que buscam interpretações teóricas e epistemológicas desse conceito, até mesmo na ciência geográfica o tema é difuso, desde a geografia clássica à geografia contemporânea, nas diferentes correntes do pensamento e escolas. Nesse sentido, nosso desdobramento está centrado nos fundamentos teórico-metodológicos dos geógrafos italianos, uma 
vez que, nas últimas décadas, têm contribuído significativamente para a interpretação e evolução do conceito de território e seus desdobramentos. Em resumo, buscamos na literatura italiana, por meio de estágio no Dipartimento Interateneo Território di Politecnico e Università degli Studi di Torino, aprofundar nos estudos sobre as concepções de território, desenvolvimento, e Sistema Local Territorial.

\section{0 território: abordagem teórico-metodólogico}

Os geógrafos da Escola Italiana vêm de longa data se dedicando às pesquisas e reflexões sobre o território. A inquietação é apontada no início dos anos de 1960 pelo geógrafo A. Sestini. Ele observava que no território italiano estava ocorrendo a destruição do meio ambiente, no período do "milagre econômico". Porém, esta questão não era discutida, pois a geografia não se ocupava de tal temática. Dematteis (2012) critica os geógrafos daquele momento, por perderem uma grande oportunidade de aplicar os conhecimentos geográficos à transformação dos territórios.

Neste período, havia um distanciamento que Dematteis (2012) caracteriza como cultural entre os geógrafos que se dedicavam a descrever sobre "as diversidades locais e regionais como invariáveis e os geógrafos urbanistas que as projetavam". Os primeiros, embora com acúmulo de conhecimento sobre esses territórios, não refletiam sobre seus valores e potencialidades. Por outro lado, os urbanistas preferiam ver "o território como uma tela branca ("faire nappe blanche", recomendou Le Corbusier a quem começava a projetar), sobre a qual projetavam as soluções dos grandes problemas da reconstrução e do boom econômico" (Dematteis, 2012, p. 13). Neste período, houve uma tentativa de convergências entre geógrafos e planejadores, por meio de disciplinas com novas abordagens e acesso à literatura anglo-saxônica da Geografia Quantitativa (baseada em analogias com as leis da física, nos modelos analíticos, dos quais os "gravitacionais" e os dos "lugares centrais"). Nos modelos, propostos pelos geógrafos, os espaços se caracterizavam como homogêneos (Dematteis, 2012).

Ainda de acordo com Dematteis (2012), o modelo analítico encontrou grande utilização no planejamento territorial urbano nas décadas de 1960 e 1970. Ele e outros geógrafos fizeram aplicação do modelo dos lugares centrais na região de Piemonte, inclusive em Turim. Essa experiência 
contribuiu para reflexão e análise crítica desses modelos. Assim, concluiu que essa geografia, "foi mais do que uma geografia sem atores [...]. A ideia de promover a geografia como 'ciência real', desvalorizando as contingências históricas em favor de representações abstratas, era extremamente simplista" (Dematteis, 2012, p. 14).

A preocupação de Dematteis com os atores sociais no espaço geográfico, já se encontrava em Gambi $(1956,1964)$

não é uma entidade pura e abstrata, nem uma área de terra ou mar, ou um pedaço de crosta da Terra que recebe o próprio homem, mas uma entidade que tem uma dignidade histórica de poder, e que muda constantemente porque o homem vive e trabalha lá e, então, apropria-se desse espaço e dá-lhe continuamente novos valores ${ }^{2}$ (Gambi, 1956 apud Dematteis, 2012, p. 15, tradução nossa).

Dematteis cita que além de Gambi, outros geógrafos italianos também apontavam em suas produções científicas, uma geografia mais voltada aos atores sociais, como G. Barbieri, F. Compagna, G. Corna Pellegrini, E. Massi, G. Merlini, C. Muscarà.

Contudo, o grande impulso se deve ao pensamento marxista, nos anos da crise Europeia entre 1960/1970. O pensamento marxista anulava a ideia de "territórios como simples estados das coisas" (Dematteis, 2012, p. 16), além de contribuir para ampliar o entendimento do espaço geográfico:

Marx contribuiu também para compreender como o espaço geográfico se transforma em território, nomeadamente, numa máquina gigantesca produtiva, poderia tornar-se algo natural, ou seja, uma estrutura impessoal, capaz de restringir a vida dos seres humanos, de alienar sua essência, para levar ao domínio da coisa sobre o homem. Foi fácil, em seguida, passar dessa teoria para a política, indicando na organização capitalista do território um instrumento de exploração dos trabalhadores por parte de quem possuía os meios de produção e o poder de decidir a gestão da terra mais adequada para a realização de reformas e lucros ${ }^{3}$. (Dematteis, 2012, p. 16, tradução nossa).

As ideias marxistas influenciaram geógrafos de vários países. $\mathrm{Na}$ Itália, essas ideias foram analisadas por F. Indovina, A. Becchi, Collidà, A. Magnaghi, B. Secchi, G. Garofoli e por Dematteis que, na ocasião, era um dos jovens geógrafos, resultando na criação do grupo informal da Geografia Democrática dos anos 1976-1980. "Não se falou mais simplesmente de espaço geográfico, mas de território” (Dematteis, 2012, p. 16). 
Nesse período, a Escola Italiana avançou na abordagem territorial à medida que colocou o território como um conceito central de suas interpretações e não o espaço geográfico, como definido por David Harvey (1980) "espaço geográfico de relações sociais". Esse rompimento foi fundamental, sobretudo, porque superou o modelo de território da geografia clássica, formulada por Ratzel, tornando-o um fenômeno humano, não mais uma área física da terra.

A avaliação dos geógrafos italianos era de que a própria geografia de concepção marxista, reconhecia que o espaço era absoluto, sem atores sociais, porém "com o risco de substituí-lo - especialmente em seus aspectos estruturalistas - por uma visão de território onde existiam apenas as relações entre os atores, enquanto o espaço concreto desaparecia ou se tornava uma simples tela, sobre a qual se projetavam as formas do espaço social (Dematteis, 2012, p. 16).

De acordo com Dematteis (2012, p. 16), em 1979 a Revista Herodoto Italiana e a Conferência em Florença, com o tema "pesquisa empírica na geografia”, foi um marco importante para pensar a pesquisa, isto é, foi relevante uma vez que reconhecem a necessidade de considerar os "sujeitos ativos das transformações" e suas relações com o meio ambiente.

Segundo Dansero e Baggiani (2011), o território, apesar das diferentes interpretações, é considerado um conceito chave nas diferentes abordagens da Geografia.

O território é um conceito central (embora com significados diferentes), nas reflexões das disciplinas como na geografia urbanista, na economia espacial, na sociologia urbana e regional.

Muitas vezes, em tais disciplinas usam como sinônimos espaço e território. Na realidade, o conceito de espaço é muito mais abstrato. O espaço está em posição anterior (lógico e temporal) em direção ao território. O espaço é a "prisão original" e o território é a prisão a que os homens são dadas.

Na verdade, nós não habitamos o espaço, nem mesmo o ambiente natural, mas um território, um ambiente que está profundamente e incessantemente transformado por ação humana ${ }^{4}$. (Dansero; Baggiani, 2011, p. 12, tradução nossa).

Os autores discorrem que, para entender a complexidade do território, é necessário entender três concepções distintas que se complementam, no entendimento dos problemas, das políticas ambientais 
e das políticas públicas. Em resumo, de acordo com Dematteis (2005) e demais geógrafos da escola, distinguem-se os diferentes significados de território e sua crescente complexidade, que geralmete estão interligadas com o discurso de desenvovimento local. Desse modo, o território pode ser pensado e enfatizado como:

a) Simples suporte, no âmbito espacial da interação entre os sujeitos- atores das ações planejadas do desenvolvimento;

b) Recepiente de recursos potenciais (material e imaterial) definidos objetivamente das especialidades externas e internas de vocação;

c) Lugar de possibilidade de exercício de governança da territorialidade ativa, que como combinação do significado a e $\underline{b}$, quando a interação dos atores (local e externos) liga-se a valorização dos recursos locais transformando-o em potencialidade utilizável e potencialmente exportável.

d) Ator coletivo local, rede de sujeitos públicos e privados, capazes de autoorganizar-se no final de autoprojetar e gerenciar o próprio desenvolvimento 5 . (Dansero, 2012, p. 206-207, tradução nossa).

Nesse sentido, o território assume centralidade, pelo menos no plano teórico, na definição de desenvolvimento local. Porém, na prática, ainda segundo Dansero (2012), é reduzido como uma categoria mitigada, quando citado raramente é discutido em profundidade. Também passa a ser um simples suporte passivo de ações, especialmente político-administrativo. Partindo dessas reflexões, a geografia italiana abriu um caminho a ser trilhado, sobretudo em termos de desenvolvimento local.

\section{Desenvolvimento: breve reflexão}

Apesar de Sanchs (2007) considerar que nos últimos cinquenta anos vivemos a era do desenvolvimento, ainda assim, temos muito que nos empenhar com pesquisas que contribuam para reflexão do desenvolvimento. Desenvolvimento do quê e para quem? Sobretudo, nesse momento de crescente globalização econômica, política, social e cultural. 
Mais de cinco décadas se passaram e a discussão do conceito de desenvolvimento, apesar de ser debatido, ainda é muito emblemática, uma vez que as teorias do desenvolvimento são sempre complexas (Hettne, 1986). Além do mais, como definir desenvolvimento uma vez que no mundo há diferentes formas de desenvolvimento. Assim, não há uma única definição para este termo, isto é, por mais que os pesquisadores busquem uma definição sempre haverá questionamentos. Para Minoia (2009), esse conceito evoluiu:

[...] dando origem a diferentes paradigmas de referência, que envolvem diversos objetivos políticos e uma visão diferente da relação entre a sociedade e o meio ambiente, do uso de recursos e critérios com a organização de um território. Por causa de seus problemas econômicos, sociais e ambientais, o termo "desenvolvimento" não é neutro, mas tem uma política forte, por isso, é importante considerar o que o define, o que seriam os seus objetivos e métodos ${ }^{1}$. (Minoia, 2009 apud Brusarosco, 2011, p. 17, tradução nossa).

O termo desenvolvimento vem de uma longa trajetória, vinculada à história ocidental e tem orientado as nações emergentes depois da Segunda Guerra Mundial (Sanchs, 2007). A consagração do termo, segundo Brusarosco (2011, p. 18), deu-se com o discurso de Harry S. Truman, no dia em que assumiu a presidência dos Estados Unidos (20 de janeiro de 1949). O presidente foi enfático, usando a palavra "subdesenvolvimento", se referindo às regiões economicamente atrasadas. Desse modo, a ideia de subdesenvolvimento nasceu como um produto pós-colonial e pósbélico, em um contexto político e econômico fortemente influenciado pela Guerra Fria, e da necessidade de os Estados Unidos conterem a influência soviética. Em outras palavras, Sanchs (2007, p. 28) analisa o discurso de Truman como uma conceituação de diretrizes para constituição de planos de desenvolvimento.

Sanchs e Hettne (1986) nos remetem à reflexão de que a teoria do desenvolvimento sempre esteve intimamente ligada às estratégias de desenvolvimento (por exemplo, mudanças na estruturação econômica e as instituições sociais, levadas a cabo para encontrar soluções consistentes e duradouras para os problemas enfrentados pelos tomadores de decisão). Do mesmo modo, trazem que a teoria do desenvolvimento teve origem a partir dos países subdesenvolvidos, com base na premissa implícita que a condição da sociedade não era satisfatória, que seria necessária uma mudança. 
Segundo Hodder (2001, p. 19-20), o desenvolvimento pode ser considerado um processo econômico, social e político que comporta um constante melhoramento da qualidade de vida de uma parcela da população. E isso implica não somente a dimensão econômica como também social e político, isto é, um processo contínuo e não apenas temporal. Os conceitos de igualdade e equidade são considerados objetivos centrais do processo de desenvolvimento.

Dansero, Giaccaria e Governa (2008), interpretando as ideias de Hettne (1986) e de Power (2003), trazem que nos estudos de desenvolvimento há duas formas de entendimento: na dimensão positiva e na normativa. Na primeira, o desenvolvimento pode ser visto como um processo histórico de mudanças sociais quando uma sociedade é analisada na sua transformação, considerando um longo período, e na dimensão normativa é vista como uma descrição, com medida, e com objetivo de uma sociedade desejável. Apositiva refere-se ao estudo do desenvolvimento como ele realmente é, e a normativa como este deveria ser.

O autor assegura que essas distinções são necessárias, independente das críticas ao conceito de desenvolvimento. Porque qualquer teoria social baseia-se de certos "valores, que podem ou não ser trazidas à luz. Portanto, a teoria do desenvolvimento deve ser explicitada e avaliada criticamente, a legislação, os fins e os meios". (Dansero; Giaccaria; Governa, 2008, p. 18).

Para Hettne (1986), a distinção entre a dimensão positiva e normativa vem de uma longa tradição, na história intelectual ocidental. O pensamento maquiavélico tem proposto uma superação entre as duas modalidades de pensamento; para um princípio, seria preferível estudar "o homem como realmente é" e não "como deveria ser". Essa última solução era prevalecente de natureza teológica. O modo de pensar "realista" emerge como um novo paradigma. A ideia que as pessoas guiadas por seus próprios interesses, culminaram com o conceito de homem econômico, que foi tomado como fundamento da ciência econômica (Dansero; Giaccaria; Governa, 2008).

Atualmente há uma tendência da dimensão normativa em pesquisas sobre problemas do desenvolvimento. Do mesmo modo, Hettne (1986) assegura que o normativismo foi causado, em parte, pelo excesso de positivismo, que é culposo de uma alta dose de banalidade e irrelevância da pesquisa. $\mathrm{O}$ contraste entre aqueles que estudam o desenvolvimento e suas manifestações concretas embasadas em certas teorias, e os 
que teorizam sobre implicações do desenvolvimento de acordo com determinados valores. Assim, conclui que a teoria do desenvolvimento deve ser explicitamente normativa e avaliar criticamente os fins e os meios em vez de procurar uma realidade oculta, em conformidade com as leis teóricas.

Para Hodder (2001), o estudo do desenvolvimento pode ser endereçado partindo de posições diversas, um campo interdisciplinar muito complexo. Todavia, é difícil estabelecer qual a mais adotada ou pertinente: economia, sociologia, agrária, política, geografia, ou outra. Assim, para um geógrafo, bem como para qualquer outro estudioso, deve haver a consciência de que um estudo sobre o desenvolvimento é apenas um complemento aos trabalhos de outros pesquisadores.

Conforme Dematteis e Governa (2005), a discussão e reflexão sobre o desenvolvimento comprovam a dimensão territorial e das políticas de sua promoção. Essas discussões, sobretudo na década de 1990, destacam o território como um ator central do desenvolvimento, especialmente do desenvolvimento local. Ambos os geógrafos aprofundaram-se nesse tema e tornaram sua Escola referência no assunto.

De acordo com os pressupostos da Escola de Turim, trata-se de um processo de interação entre sujeitos locais (públicos, privados e suas várias parcerias) que compartilham, de modo implícito e explícito, alguma visão de desenvolvimento, para comissionamento e valorização dos recursos, as riquezas materiais e imateriais dos territórios.

\section{Sistema local territorial}

Uma das inquietações da Escola era como traduzir esses conteúdos teóricos em um instrumento prático, que fosse capaz de contribuir para análise, avaliação aplicável ao plano de ações de desenvolvimento local territorial. Neste sentido, desenham um modelo conceitual denominado de Sistema Local Territorial (SLOT).

Segundo Saquet (2007, p. 112), nesse sistema, Dematteis e Governa (2005) revelam preocupação com as relações geográficas tanto verticais, quanto horizontais, isto é, "com as condições e com as articulações territoriais para o desenvolvimento”, em especial a discussão do SLOT. Assim, SLOT foi definido como uma rede local de sujeitos que em função de relações específicas interagem entre si e com o meio, onde trabalha e 
age, como uma entidade coletiva (Dematteis; Governa, 2005). Em outros termos, trata-se de um "conjunto dotado de identidade, sendo que os sujeitos que o compõem são capazes de definir comportamentos coletivos; o local é um nó articulado em redes tendencialmente planetárias, na forma de acoplamento de relações recíprocas e unidades" (Saquet, 2007, p. 112).

Em termos gerais, o SLOT se propõe a descrever a relação entre a interação social, potencialidades dos territórios, governança e o desenvolvimento. Dessa forma, o SLOT é pensado como constituído de dois conjuntos de componentes, rede local de sujeitos e o milieu (ambiente) territorial local, bem como de três conjuntos de relações. As relações são entre os sujeitos, os sujeitos com o ambiente e a relação entre os componentes locais com as escalas supralocais (Dematteis; Governa, 2005, p. 29). Essas relações são, tanto endógenas, como exógenas, embora distintas, também se relacionam.

Desse modo, Dematteis e Governa (2005) destacam que essa rede de sujeitos locais para desenvolver as suas relações internas, que são relações de cooperação, de negociação, de competição e de conflitos, faz-se necessário um planejamento de ações coletivas com vistas ao alcance das metas para o desenvolvimento. Por sua vez, a valorização das iniciativas endógenas que atuam por meio das relações demanda o desenvolvimento de relações transescalares, com redes supralocais de sujeitos públicos e privados. Uma vez que estas relações comportam a ativação dos fluxos, entrada e saída (de informação, capital, pessoas, matéria e energia). O modelo permite também questionar a abordagem multiescalar dos sistemas locais com os mais vastos sistemas econômicos e com os ecossistemas locais.

Para discutir o SLOT é necessária a compreensão das relações econômicas, uma vez que essas contribuem para o entendimento dos novos processos territoriais. Tal abordagem já se encontrava em algumas publicações desde a década de 1960. Dematteis e Governa (2005) apresentam argumentos sobre as condições do desenvolvimento econômico, sobre os territórios. Essa discussão também aparece em outras obras nas áreas de Sociologia e Economia, demonstrando uma interação interdisciplinar.

Dematteis (1994) discutia a relação do espaço físico com os acontecimentos históricos, o que para ele contém uma conotação metafórica. Nessa perspectiva, considera os elementos naturais e 
os processos históricos, isto é, as conexões e os diferentes níveis. Do mesmo modo, abordava a relação espaço e tempo à compreensão do desenvolvimento econômico.

No SLOT, há relações entre os sujeitos e desses com o ecossistema local, pensamento que surgiu e teve os primeiros sinais na organização do grupo de geógrafos democráticos na década de 1970, citado anteriormente. Nas décadas seguintes apareceram novos grupos de pesquisas que intensificam os desdobramentos teórico-metodológicos e sua utilidade prática.

O Sistema indica potenciais que se realizam na abordagem entre componentes objetivos e subjetivos. Ao longo do tempo, esse instrumento permite identificar o estado atual da relação território/sujeitos/ações na prospectiva de ativar um sistema local como um ator coletivo; avaliar a priori a possibilidade de ativar o processo de desenvolvimento autocentrado e, a posteriori o valor territorial; sugerir uma edificação mais adequada, a cada caso, um sistema de governança eficaz para atuação das políticas e para a realização de programas e projetos em uma ótica multiescalar; identificar possibilidades de redes de sistemas locais (cidades, distrito etc.) como estrutura de base ao desenvolvimento regional; avaliar a sustentabilidade territorial do desenvolvimento, a intensa capacidade de reproduzir e para enriquecer o capital local territorial, sem esgotar ou empobrecer outros territórios. (Dematteis; Governa, 2005, p. 31).

Dematteis (1999) entende o território como projeção e como natureza, para além das dimensões sociais, ou seja, considera os fatores físicos, históricos e culturais que influenciam no desenvolvimento local. Em síntese, o território é condição de processos e de desenvolvimento. Entende que a natureza e sociedade se manifestam de forma específica em diferentes lugares. $\mathrm{O}$ autor também avalia que a fertilidade do solo, o clima, os atrativos paisagísticos, a estratificação social, a cultura familiar específica, as tradições de empreendimentos, as associações de moradores, as relações sociais, as posses, as propriedades, as redes de circulação e comunicação devem ser consideradas nesse processo.

Ainda de acordo com Dematteis (1994), o território compreende várias dimensões, econômica, cultural, política e natural, são formas espaciais, relações entre sujeitos e redes. Destaca o papel das redes globais, a relação dessas com as redes locais, percebendo que essas relações são de complementariedade e não de eliminações dos territórios. Tal entendimento sobre as redes e conexões é fruto de um processo histórico, caracterizado pela fase de alta concentração da população urbana, em 
algumas regiões da Itália, na década de 1970. Em 1992, Dematteis e C. Emanuel apontam essa tendência, além de valorizarem as pequenas e médias cidades como estratégias de desenvolvimento local, efetivado em redes. Em suma, o grupo se preocupa em destacar as relações sociais, a natureza, as transescalaridades efetivadas pelas redes de circulação e comunicação.

Em 1999, Dematteis retoma e melhora a ideia de reciprocidade entre sociedade e território.

As transformações territoriais urbanas, por exemplo, não são as consequências de mudanças que acontecem separadas do território. Nada se pensa, muda ou se faz, que não seja por meio da materialidade dos lugares; é através dela que passam, necessariamente, todas as relações sociais, as representações conceituais e as iniciativas de projetos de desenvolvimento local.(Dematteis, 1999, p. 120).

Esse entendimento é partilhado por Claude Raffestin e Ângelo Turco, como a mediação simbólica, cognitiva e prática, que a materialidade dos lugares exercita sobre o agir social. É uma territorialidade ativa, ou seja, é a valorização das condições e recursos potenciais de contextos territoriais em processos de desenvolvimento (Saquet, 2007).

A territorialidade ativa é entendida sob o ponto de vista do planejamento e da organização política, porque se trata de um fato social, envolvendo indivíduos que fazem parte de grupos que interagem entre si, mediados pelo território. Na relação dialética do espaço/tempo, conjuntamente, não dependem somente do Sistema Territorial, mas de relações intersubjetivas, ou seja, das relações entre os sujeitos e outros sujeitos e/ou sujeitos e objetos. Há redes locais de sujeitos que interligam o local com outros lugares do mundo e estão em relação com a natureza. Segundo Demateis (1999, p. 121), "essas relações dão identidade ao lugar, numa espécie de território patrimônio”, no dizer de Bourdin (1994) no qual há definição de atores, cooperação, participação e mobilização. Nesse sentido, o agir social é local, territorial e significa territorialidade, e o autor também destaca que

os planos e as políticas de desenvolvimento devem partir de uma geografia que reconheça as relações, ou seja, Geografia da Territorialidade, podendo ser uma geografia das possibilidades de desenvolvimento, sendo que as redes de sujeitos (indivíduos e coletivos) são instrumentos conceitual e operativo para governar a territorialidade. (Saquet, 2007, p. 115). 
Magnaghi (2010) também fez importantes discussões e reflexões sobre os conceitos de território, territorialização, sustentabilidade, desenvolvimento local e autonomia, considerando especialmente a interação dos indivíduos, as políticas de redes. Em sua obra Il progetto locale, Magnaghi faz uma abordagem, processual e relacional do território, do desenvolvimento e de sua territorialização (Saquet, 2007).

Mais recentemente, Dematteis, Giaccaria e Governa (2008) aprofundam a reflexão sobre a sustentabilidade cultural dos sistemas locais territoriais, isto é, questiona se há uma sustentabilidade cultural. Contudo, analisam a forma de desenvolvimento territorial resultantes de projetos implementados por um ator coletivo que interage com atores externos, portadores de valores e recursos "mobili" (cultural, cognitivo, tecnológico, financeiro etc); que combina com valores e recursos "immobili" próprios do território; que se orienta no seu domínio cognitivo e regulador que produz assim um valor (cultural, social e econômico) superior àquele, senão interviesse na relação de territorialidade ativa, este valor, denominado de 'adicionado territorial' (aggiunto territoriale) permite reproduzir o recurso do sistema local, assegurando a sustentabilidade do seu desenvolvimento (Dematteis; Giaccaria; Governa, 2008, p. 247). A expressão de valor é encontrada em Dematteis e Governa (2005), ambos chamam atenção para o duplo significado, um de transformação e valor de uso dos recursos potenciais (immobili específico) de um território e outro de incorporar ao território novo valor sobre forma de incremento de capital territorial.

A dimensão ou adjunta "cultura" se refere às ações dos grupos humanos, que desenvolvem relações sociais, específicas, internas entre si e com outros, onde interagem de forma co-evolutiva com o específico, meio material e simbólico, de tal modo, elaboram, acumulam, reproduzem conhecimentos e habilidades, crenças, costumes, expressão artísticas, instituições e regras morais e legais. Dematteis (2008) destaca a superação da visão do uso corrente, aonde a cultura é entendida em termos de produto ou uma expressão simbólica, separada do contexto material da qual é derivada. Para Dematteis, Giaccaria e Governa (2008, p. 248), trata-se de um "processo que dá origem à expressão cultural diversificada no tempo, reproduzindo a variedade cultural compressiva, intensa como patrimônio geral da humanidade”. Assim, defende a ideia de que o valor cultural de interesse mais geral não está no componente individual ou somente na expressão cultural, mas nas variedades e nas sintonias ou reciprocidades, 
uma vez que esta é resultado das especificidades dos sistemas locais autoorganizados. Em síntese, um desenvolvimento culturalmente sustentável se consente na reprodução diversificada dos sistemas locais.

\section{Considerações finais}

Após análise da produção científica dos geógrafos da Escola de Turim, observamos quão são importantes suas reflexões sobre o território, desenvolvimento local e Sistema Local Territorial, especialmente porque as inquietações apontadas na década de 1960 retratavam sobre a destruição do meio ambiente provocado pelo avanço econômico, especialmente no norte da Itália. Apesar do distanciamento dos geógrafos e as convergências entre os seguidores da literatura anglo-saxônica, fundamentados na Geografia Pragmática que se dedicavam aos modelos analíticos no desenvolvimento do planejamento territorial. Contudo, essa corrente logo serviu para reflexões de sua utilização. Dematteis foi um dos críticos, enfatizando que esta Geografia desvalorizava as contingências históricas e sociais.

O pensamento marxista, entre as décadas de 1960 e 1970, também teve grande influência sobre o pensamento dos geógrafos na interpretação dos territórios, com a organização capitalista, e pela exploração dos trabalhadores pelos donos dos meios de produção, as relações de poder, bem como a compreensão da transformação do espaço geográfico em território. Nesse período, a escola italiana avança nas interpretações territoriais, e elege o território como um conceito central. Fato que contibuiu para tornar a Geografia Italiana como referência nos estudos territoriais.

A escola Turinesa de Geografia faz importantes contribuições no campo teórico e prático acerca do território e seu desenvolvimento. Dentre as quais, o entendimento dos problemas que assolam o território, as políticas ambientais e as políticas públicas. Essas reflexões abriram caminhos para serem trilhados em termos de desenvolvimento local. Os esforços foram fundamentais para a teorização do Sistema Local Territorial, que de fato se trata de um instrumento prático para avaliação das ações de desenvolvimento do território.

Apesar do avanço desses geágrafos, no que tange o terrritório e seu desenvimento, ainda há muito que ser discutido e debatido em razão da crescente globalização, pois amplia a necessidade de análise dos territórios e de suas concepções teóricos metodológicas. 


\section{Notas}

1 Texto original em italiano.

2 Texto original em italiano.

3 Texto original em italiano.

4 Texto original em inglês.

5 Texto original em italiano.

\section{Referências}

BIGNANTE, E.; DANSERO, E.; SCARPOCCH, C. (Org.) Geografia e Cooperarazione allo sviluppo - Temi e prospettive per un approccio territoriale. Torino: Franco Angeli, 2009.

BOURDIN A. Le patrimoine reinvente. Paris : PUF, 1984.

BRUSAROSCO, A. Geografia e Cooperazione: i projetti di sviluppo rurale della cooperazione italiana in Bosnia Erzegovina. 2011. 354 f. Tese (Dottorato in Scienze Storiche) - Università degli Studi di Padova. 2011.

DANSERO, E. Energie da Contraddizione: Innovazioni rurali e território riflessioni da alcuneesperienze in Italia e in Piemonte. In: SAQUET, M; DANSERO, E. CANDIOTTO, L. (Org.). Geografia da e para a Cooperação ao Desenvolvimento Territorial: Experiências Brasileiras e Italianas. 1. ed. São Paulo: Outras Expressões, 2012. 207-230

; BAGGIANI, M. Politiche per L'ambiente - Dalla Natura al Territorio. 2. èd. Torino: UTET, 2011.

DEMATTEIS, G. Città delle Alpi: distinte e connesse. Società dei Territorialisti, 2012.

; GIACCARIA, P.; GOVERNA, F. Losviluppo locale alnord e al sud. Un confronto internazionale. Milano: Franco Angeli, 2008.

; PUTTILLI, M. Territory and energy sustainability: the challenge of renewable energy sources. Journal of Environmental Planning and Management, v. 53, 2010.

DEMATTEIS, G. Possibilità e limiti dello sviluppo locale. Sviluppo locale, n.1, p. 10-30, 1994.

. Sul crocevia della territorialità urbana. In: dèlla città - Tesi a confronto. Milano: Angeli, 1999. . et al. (Org.). I futuri

; GOVERNA, F. (Org.) Territotialità, Sviluppo Locale, Sostenibilità: Il Modello Slot. Milano: Franco Angeli, 2005.

HARVEY, D. A Justiça Social e a Cidade. São Paulo: Hucitec, 1980

HETTNE, B. Le teorie dello sviluppo e ilterzo mondo. Roma: Asal,1986. 
HODDER, R. Geografia dello sviluppo - Le ragioni delle disugualglianze nel contesto dell'economia globale. Milano: De agostini, 2001.

MAGNAGHI, A. Il Progetto Locale. Verso la coscienza di luogo. Torino: Bollati Boringhieri, 2010.

POWER, M. Rethinking development geographies. London: Routledge, 2003.

RAFFESTIN, C. Por uma Geografia do poder. São Paulo: Ática, 1993.

SANCHS, W. Dizionario dello sviluppo. Torin: Ega, 2007.

SAQUET, M. A. Abordagens e concepções de territorio. 1. ed. São Paulo: Expressão Popular, 2007.

STOCCHIERO, A.; COLETTI, R.; MEZZETTI, P. La cooperazione decentrata dei Comuni metropolitani. Roma: CESPI Working Paper, 2005.

Áurea Andrade Viana de Andrade - possui graduação em Geografia pela Universidade Estadual do Paraná. Mestrado e doutorado em Geografia pela Universidade Estadual de Maringá. Estágio no Dipartimento Interateneo di Scienze, Progetto e Politiche del Territorio da Università Politecnico di Torino, Italia. Atualmente é Professora Adjunta da Universidade Estadual do Paraná, campus de Campo Mourão.

Elpídio Serra - possui graduação pela Universidade Estadual de Maringá, mestrado e doutorado em Geografia pela Universidade Estadual Paulista Júlio Mesquita Filho, Rio Claro. Pós-doutor em Geografia pela Universidade Estadual Paulista Júlio Mesquita Filho, Presidente Prudente. Atualmente é professor associado da Universidade Estadual de Maringá.

\section{Contribuições dos autores}

Aurea Andrade Viana de Andrade contribuiu por meio do Estágio no Dipartimento Interateneo di Scienze, Progetto e Politiche del Territorio da Università Politecnico di Torino, onde foi possível o contato direto com os geógrafos e acesso ao referencial teórico. A contribuição para o artigo está diretamente ligada à tradução e à interpretação do referencial teórico e da elaboração do texto. Elpídio Serra participou das discussões e reflexões para melhor interpretação do referencial teórico e da elaboração do texto. 